This is the version of the chapter accepted for publication in The Oxford Handbook of the Ethiopian Economy published by Oxford University Press: https://global.oup.com/academic/product/the-oxford-handbook-of-theethiopian-economy-9780198814986? cc=gb\&lang=en\&

Accepted version downloaded from SOAS Research Online: http://eprints.soas.ac.uk/30108

Deborah Johnston and Helen Walls

\title{
Abstract
}

Ethiopia has an integrated approach to addressing nutrition. However, greater clarity is needed on the wider impact of policy on food and nutrition. We focus on the interrelationship between economic policy and nutrition policy (defined as including all food- and nutrition-relevant policy). While Ethiopia's policy has had notable successes, particularly with addressing stunting, two key challenges remain. First, some indicators such as wasting and anaemia in children under five have shown far less improvement. Second, the bottom quintile of children has seen far more limited general improvement than the population as a whole. We argue that the focus of government policy needs to shift from food availability to broader issues of food acquisition and particularly food affordability, which is mediated through food prices and waged employment.

Of particular concern is the rising price of animal-source products and other non-staple foods, which may be related to the challenges of addressing some nutritional indicators.

Keywords

Ethiopia, nutrition, nutrition security, food security, nutrition policy, food policy, food environments, food price, diet quality, dietary diversity 


\title{
Chapter 22
}

\section{Economic Policy and Food Security in Ethiopia}

\author{
Deborah Johnston and Helen Walls
}

\subsection{INTRODUCTION}

Ethiopia has an integrated approach to addressing nutrition; however, there is little clarity about the wider impact of government policy on food and nutrition. In this chapter we focus on the interrelationship in Ethiopia between economic policy broadly conceptualized and nutrition policy (defined as including all food- and nutrition-relevant policy). Overall, there have been notable successes in nutrition policy in Ethiopia, but significant challenges remain. If these challenges are to be met successfully, greater consideration of how to address rapidly changing food systems in Ethiopia is needed at national policy level. We argue that the focus of government policy needs to shift from food availability to broader issues of food acquisition and particularly food affordability, which is mediated through food prices and waged employment.

Historically, food and nutrition security in Ethiopia have arguably been addressed by national policy, predominantly in relation to improving food production and emergency food aid responses. This reflects the extent of drought and famine that Ethiopia has faced, including devastating events such as the 1983-5 famine, which is estimated to have led to up to a million deaths and received attention globally. Today, despite improvements in child stunting and wasting, undernutrition remains a significant challenge in Ethiopia (see Chapter 23). Furthermore, recent studies describe how Ethiopia is also facing an increasing prevalence of 
overweight, obesity, and related non-communicable diseases (NCDs) in urban settings (Zello 2015; Tebekaw et al. 2014). Thus, Ethiopia is now beginning to experience what is referred to as the 'double burden' of malnutrition: the co-existence of underweight and micronutrient deficiencies, as well as overweight, obesity, and NCDs (Baker et al. 2018; Walls et al. 2016).

Official data point to substantial improvements in nutrition between approximately 2000 and 2015, but with some exceptions (FDRE2016). We interrogate this data in more detail below, and find three areas of particular concern. First, high levels of malnutrition do remain. Worst affected by malnutrition and food insecurity are the close to 30 per cent of Ethiopia's population living below the poverty line of US\$1.25 a day (USAID 2016). Recent USAID figures indicate that 10 million more people are in need of emergency food assistance in 2016 (USAID 2016). Second, some indicators such as childhood anaemia worsened significantly after 2015 . Third, where the data can be disaggregated, there is evidence that the poorest have not benefited as substantially in those indicators which have improved.

Furthermore, Ethiopia has in recent years, in 2008 and 2011, experienced 'spikes' in food prices (Admassie 2014: 138; Headey et al. 2012). In 2008, Ethiopia had the highest rate of month-on-month inflation in key food groups among low- and middle-income countries, at 3.5 per cent per month (Headey et al. 2012). This food price inflation was driven by higher prices of staple foods such as maize, wheat, and teff. Admassie (2014: 140) reviewed a range of studies that suggest that after the 2008 price spike, poverty levels in Ethiopia rose, and consumption fell, particularly among the poorest households.

This mixed picture suggests a need to understand better the relationship between economic growth, food, and nutrition security in Ethiopia. In the following, we draw on analytical approaches in key academic texts to assist our examination of the relationship between economic 
growth and the achievement of food and nutrition security, drawing on several key national policy documents.

\subsection{ESTABLISHING A CONCEPTUAL APPROACH FOR POLICY EXAMINATION}

The UNICEF conceptual framework (Smith and Haddad 2015), of which caring practices and changes to the wider health environment form a key part, is a commonly used approach to understand nutrition outcomes. This framework outlines the factors leading to malnutrition, including the factors that shape and mediate the effects of dietary intake: adequacy of access to food; adequacy of care practices, particularly for women and children; and adequacy of health services and wider environments affecting health. However, the UNICEF approach does not provide for an understanding of how dietary intake and adequacy of access to food are determined. This is particularly important as 'nutrition-sensitive' interventions are considered to be key to improving nutritional outcomes - 'nutrition-sensitive' interventions being interventions for which the primary objective is not nutrition, but that have nonetheless been designed to achieve nutritional objectives and address the underlying causes of malnutrition (as opposed to 'nutrition-specific' interventions, the primary objective of which is to address nutrition) (Ruel et al. 2013).

To assist our examination of nutrition in Ethiopia, we develop a new conceptual framework for examining the determinants of food environments and how they shape food acquisition and nutrition outcomes. Ultimately, people's food acquisition is a result of their interaction with local food environments. Swinburn et al. (2013) defined the food environment as the 'collective 
physical, economic, policy and sociocultural surroundings, opportunities and conditions that influence people's food and beverage choices and nutritional status' (Swinburn et al. 2013: 2). Furthermore, Turner et al. (2017) have defined a set of measurable dimensions of food environments, and a conceptualization that provides for two inter-related aspects of food environments, distinguishing between:

- the 'external food environment', relating to: food availability, food price, vendor and product characteristics, and food marketing and regulation; and

- the 'personal food environment', relating to: accessibility (for example, physical distance to food sources, time, and transport), food affordability, convenience, and desirability.

Both notional and effective demands are thus a function of characteristics of the food environment — both the 'external' and 'personal' characteristics (Turner et al. 2017). To understand the factors that influence these various aspects of the food environment, we draw on the work of Sen (1981), who described a framework for understanding effective demand, and Fine (1997) who provides a theoretical challenge to the framework of Sen.

In his entitlement approach to famine, Sen identifies four key factors influencing the effective demand for food — and, essentially, food environments. These are: production-based entitlements (i.e. consumption of food produced from one's own garden or field); trade-based entitlements (i.e. food purchase funded by the income from sales of another product, such as a cash crop); own-labour entitlements (i.e. food purchase funded by waged income); and transferbased entitlements (i.e. food access through gifts, food aid, etc.). Importantly, Sen's approach shifts attention away from food availability per se, focusing attention instead on those factors affecting effective food demand. 
Fine (1997) has argued that much of the dissent over Sen's work stems from disagreements over underlying implicit theoretical propositions that themselves are not readily apparent in the entitlement framework. Specifically, Fine argues that a focus on effective demand for food needs to be combined with an understanding of how various kinds of demand emerge in a political economy context, including:

(i) how own production is related to land access and production;

(ii) how wages and employment are determined;

(iii) how, and at what prices, food is produced, processed, and distributed through national and international processes;

(iv) how the state provides food aid, transfers, and generally responds to food crises;

(v) how international agencies operate.

Also important to this discussion is the work of the various political economists who have described the role agriculture plays in the process of industrialization. Eschewing the comparative static approach to sectoral growth of mainstream economics, many political economy writers have focused on the long-term synergies between agrarian transformations and capitalist development (see also Chapter 49). On the interaction of the agricultural and industrial sectors, Kay (2009) has concluded: 'In a dynamic understanding of poverty and development, the key aspect is . . . attainment of a dynamic interaction and synergies between both sectors.' There are a range of interactions between these two sectors, such as transfers of labour, raw materials, and finance. However, agriculture is seen as having a key impact on industrial growth through its role in producing affordable food (Kay 2009). The impact of cheap food is mediated through two pathways: the effect on real wages (and therefore on the potential for accumulation in industry); and through the creation of domestic demand for non-food products (through the 
impact on disposable income). In the early stages of industrialization, agriculture's contribution to this industrialization is thus crucial (Kalecki 1993).

The frameworks described earlier help with understanding how food environments, and food and nutrition security, may be affected by a wide range of social, economic, and political changes. Therefore, to examine how state policy influences the determinants of local food environments (and thus food and nutrition security), we focus on four areas that the work of both Turner and Fine suggest affect both the structure of effective demand and the nature of the food environment:

- Own production

- Wages and employment

- Food processing and market distribution

- Food transfers through government and international agency operation

We will use these domains to examine how state policy influences the various aspects of food environments in Ethiopia, and thus the interrelationship between economic and nutrition policy in Ethiopia.

\subsection{TRENDS IN FOOD AND NUTRITION OUTCOMES IN}

\section{ETHIOPIA}

Several key nutrition indicators improved in Ethiopia from 2008 onwards, the most significant being the improvement in child stunting (see also Chapter 23). Table 22.1 also shows declines in the prevalence of wasting, underweight, and anaemia in children aged under five years. 
While Table 22.1 describes a positive picture for some indicators, there are two key concerns. First, data collected in 2016 suggest that childhood anaemia began to rise again rapidly (CSA/ICF 2016). Second, where the data can be disaggregated by asset quintile, there is evidence that overall, the bottom quintile experience a much smaller improvement than the population average (see Table 22.1).

<COMP: INSERT TABLE 22.1 NEAR HERE>

Hirvonen et al. (see Chapter 23) argue that exclusive breastfeeding, latterly as an outcome of Ethiopia's National Nutrition Programme (NNP), the first version of which covered the period 2008-13 (Ministry of Health 2015), has been a key driver of improvements in child stunting, while further improvements are challenged by poor dietary diversity in complementary feeding for infants. Their research, using a dietary diversity score compiled from DHS data, confirms the findings of other studies that suggest a range of nutrition problems in Ethiopia are due to reliance on a diet dominated by carbohydrates. The low intake of other macro- and micro-nutrients has been documented (FMoH/UNICEF/EU 2016), with data showing a concentration of food consumption on cereals, tubers, and pulses, with iron deficiencies driven by low intake of animal-source protein. Alongside a mixed record on nutrition outcomes, there has also been a volatile dependence on food imports over the period (2005-13).

<COMP: INSERT TABLE 22.2 NEAR HERE>

As shown in Table 22.2, the data on food imports suggest a significant rise in food imports around the time of the food price spikes of 2008 and 2011. The relationship between imports and agricultural performance is complex. In Ethiopia, agricultural imports have been rising while agricultural exports have also risen, partially reflecting an expansion of non-traditional agricultural exports, such as cut flowers and teff (Mulugeta 2010). 
UNCTAD (2003) argues that three factors have been increasing the rate of growth of food demand in Africa: rapid population growth, rapid urbanization, and rising income. Hassen et al. (2016) note that high recent urbanization rates in Ethiopia suggest 30 per cent of Ethiopia's population are expected to be living in cities in 2028. Using household expenditure data, Hassen et al. (2016) suggest that more affluent consumers demand more variety and choice, consume more processed and ready-to-eat foods, and pay more attention to food quality and safety. They conclude that urban dwellers allocate a much larger share of their food budget to animal products than rural dwellers (14.3 per cent versus 9.8 per cent). Similarly, the average household in an urban area consumed $11 \mathrm{~kg}$ of oils and fats per adult equivalent, while the corresponding figure for the average rural household was $4 \mathrm{~kg}$. The consumption of fruit and vegetables is also considerably higher in urban areas.

These trends are reflected in changing patterns of food imports (USDA 2016). Palm oil, sugar and sweeteners, and wheat were the three largest agricultural imports by value in Ethiopia in 2015. The USDA (2016) finds that from 2010 to 2015, imports of palm oil doubled to nearly US\$425 million, wheat imports climbed 20 per cent to over US\$360 million, while imports of sugar and sweeteners grew 65 per cent to almost US\$180 million. In addition, imports of rice, prepared foods, distilled spirits, pasta, and vegetable oil showed significant growth (USDA 2016). Over the six-year period from 2010 to 2015, rice imports increased six-fold, prepared food imports quadrupled, distilled spirit imports doubled, and pasta imports increased seven-fold.

\subsection{CHANGING NUTRITION POLICY IN ETHIOPIA}

Ethiopia's political administrative structures to address nutrition policy have been shaped by the cycle of drought and famines that the country has historically experienced (Keller 1992; de Waal 
1996; Webb and von Braun 1994). Thus, nutrition policy responses in Ethiopia have historically focused on acute or emergency food shortages. Examples of such policies include the establishment of a surveillance system for food security and acute malnutrition through the Disaster Prevention and Preparedness Commission (FDRE 2016), and the 1996 National Food Security Strategy (FDRE 1996). However, there have been efforts in recent years to establish broader, more systematic policy responses to nutrition in the country. For example, in 2005 a study of the underlying causes of malnutrition was conducted by the MoH and Ministry of Agriculture (MoA) in collaboration with UNICEF (Benson 2005), and this formed the basis for the National Nutrition Programme (NNP).

\subsection{THE EVOLUTION OF THE NATIONAL NUTRITION PROGRAMME}

This progression of the policy landscape for nutrition is reflected in Ethiopia's first National Nutrition Programme (NNP) (FDRE 1996), which acknowledged the role of multiple sectors including health, agriculture, education, and social affairs, in addressing nutrition (Ministry of Health 2015). With its focus on multisectoral coordination, this more comprehensive nutrition policy thus includes greater clarity regarding the role of economic growth and development in improving nutrition.

The evolution of policy appears to have been influenced by greater recognition internationally of the way that economic policy influences food and nutrition security, with nutrition policy now widely considered to involve, at a minimum, collaboration between the

agriculture, health, and environment sectors (Gillespie et al. 2013; Mendis 2010; Reinhardt and 
Fanzo 2014). Thus, 'nutrition-sensitive' interventions are considered to be key to improving nutritional outcomes (Ruel et al. 2013).

Despite this recognition of the need for coordinated policy, the first version of the NNP was judged to have been unsuccessful in developing multisectoral strategies (FDRE 2013). As a result, the NNP was revised (resulting in NNP-I, covering 2013 to 2015) to give a greater focus on 'the multisectoral and multidimensional nature of nutrition' with the recognition that broad economic policy is key (FDRE 2013: 15). Three high-level indicators were set: 1) reduce the prevalence of stunting from 44.4 per cent to 30 per cent by 2015 ; 2) reduce the prevalence of wasting from 9.7 per cent to 3 per cent by 2015; and 3) reduce the prevalence of chronic undernutrition in women of reproductive age from 27 per cent to 19 per cent. These were to be achieved through:

- agricultural policy: increases in production and improvements in seeds and technology; biofortification of staple foods (such as maize and sweet potato) (FDRE 2013: 26-7);

- industrial policy: the support of food production generally, and fortified food in particular; and ensuring local food quality and safety (FDRE 2013: 27-8);

- trade policy: better regulation of imported food items, and encouraging the importation of fortified food; and improving awareness of the benefits of fortified food (FDRE 2013: 128);

- social protection policy: implementing gender-sensitive safety net and credit programmes (FDRE 2013: 1-29); and

- finally, a group of disaster-preparedness interventions were designed to strengthen early warning systems and improve community participatory risk assessments (FDRE 2013: 129). 
The government of Ethiopia sought to integrate NNP (and NNP-1) with the overarching national strategic framework, the Growth and Transformation Plan 2010/11-2014/15 (GTP-I) (FDRE 2011). Overall, the GTP provides a coherent set of mandates for sectoral action, and establishes targets within a five-year timeframe for each sector. GTP-I (2010-15) did not, however, explicitly reference nutrition, instead focusing on food-related targets, including cereal production targets, food reserve targets, and the number of people assisted by the Productive Safety Net Programme (FDRE 2011, Table 19).

Section 22.6 evaluates the success of these initiatives using our conceptual approach, and introduces critical literature. However, at this stage, it can be concluded that this period between 2010/11 and 2014/15 focused on the ability both to respond to acute nutrition crises through disaster preparedness (and enhanced food reserves) and to deal with chronic food security issues through agricultural productivity enhancement. Social protection support and other interventions to address food acquisition played a more limited role, with reductions planned in the percentage of households enrolled in the productive safety net scheme. These characterizations will be examined further below using the conceptual framework.

\subsection{EVALUATING THE INTERRELATIONSHIP}

\section{BETWEEN ECONOMIC POLICY AND NUTRITION}

\section{POLICY IN ETHIOPIA}

This section describes the effectiveness of Ethiopian national policy in terms of the interrelationship between wider economic policy and nutrition outcomes. It should be read in 
conjunction with Chapter 23, which focuses on the evolution of nutrition-specific interventions to improve nutritional outcomes.

\subsubsection{Own Production}

Although the agricultural sector as a whole achieved a rapid rate of growth between 2010/11 and 2014/15 - a 6.6 per cent annual average growth rate - this fell short of the 8 per cent annual average growth target (FDRE 2016a). Generally, GTP-II suggests that agricultural productivity did not rise as much as planned due to lower increases in the applications of agricultural inputs, such as fertilizer and improved seeds (FDRE 2016a: 25).

Given this growth, however, some of the improvements in nutrition and food outcomes shown in Table 22.1 are likely to have resulted from improvements in own production of food. There are two caveats about the limited impact of these improvements on overall nutrition: that this domain is one of five that affect food environments; and that own production alone is limited in its ability to address dietary diversity.

First, the data described previously show that food consumption is increasingly influenced by food purchased. From the trends in food imports, we can see a picture of a growing role for new and processed food in Ethiopian diets, especially to meet the demand from growing urban and middle-class populations. However, it is important that we do not ignore the role of purchased food more generally in Ethiopian food provisioning, including in rural areas. Using rural household survey data from 2004-6, Klugman (2007) estimated that about half the rural population are net buyers of food. Alternatively we can use data on household consumption to calculate the share met by own-food production. Hassen et al. (2016) have undertaken this exercise for data from the 2011 household survey and found that for an average rural household, 
only about 40 per cent of rural food consumption comes from own production. Neither Klugman (2007) nor Hassen et al. (2016) have disaggregated their results for the poorest rural households, who may be landless or have limited agricultural output or access to agricultural extension or improved inputs and so are likely to source even less of their food needs from own production (see Chapter 18).

Second, the diversity of own production will be important to improve diet quality. While the majority of farmers focus on staple production, own-food entitlements are unlikely to provide the dietary diversity necessary for improved nutritional outcomes (Hassen et al. 2016). More emphasis is needed on diversification for those rural households that are dependent on own consumption of food. Alternatively, marketed production of staples must rise, allowing households to purchase other more nutritious foods in order to achieve more diverse diets.

The analysis by Hassen et al. (2016) of 2011 household food expenditure data suggests that for average rural households, 34 per cent of food purchases were funded by the sales of agricultural output. This finding is complemented by that from other studies, such as Kuma et al. (2018), which provides evidence on the role of coffee sales for food security. Data on rising exports of agricultural products (discussed above) suggests that there have been increasing marketing opportunities for agricultural products in rural Ethiopia. For some staple products, export bans were introduced during food price spikes and then lifted. For other products, new 'non-traditional' markets have emerged although these are likely to have been less important for smaller-scale farmers, and high-value crops did not meet their growth targets in GTP-I (FDRE 2016a).

Complex dynamics do exist where these export crops are also domestic food crops, with the potential for increased income for net sellers being offset by the potential for income losses by 
net buyers. Teff, the major staple of Ethiopia, is a case in point. Its status as a new 'superfood' had led to concerns that the lucrative teff export market has been the cause of sharp price rises on local markets. Despite its success in earning scarce foreign exchange, there have been some criticisms of the partial lifting of the export ban on teff, with a concern that, however sensitive the policy was to nutrition concerns, its impact will be to reduce food security (Secorun 2016; Reda 2015).

\subsubsection{Wages and Employment}

We have seen above evidence of changing food provision trends in Ethiopia, with a shift towards processed and purchased food. Using 2011 household expenditure data, Hassen et al. (2016) find that approximately 25 per cent of all food in average rural households is paid for by remittances, sales of non-agricultural products, and wage income. ${ }^{1}$ This figure is higher in urban areas, where 40 per cent of food expenditures were paid for by wage income in the same survey.

These data show the importance of charting trends in real food prices and understanding the reasons for food price spikes. Headey et al. (2012) suggest particularly high food price rises in Ethiopia compared to other developing countries. Using household expenditure data, Hassen et al. (2016) suggest that the average price paid per calorie increased by 8 per cent between 1996 and 2011 in real terms. However, there were sharp differences in the trends for different food items. Hassen et al. (2016) suggest that the real prices paid for calories from cereals were 20 per

\footnotetext{
${ }^{1}$ The source of remittances is unclear in this survey and these are likely to come from the waged employment of family members in other parts of Ethiopia or internationally. Also these shares are likely to be higher for the poorest rural households, where the importance of wage and remittance income is often underestimated (Cramer et al. 2014).
} 
cent lower in 2011 than the price paid in 1996, while the real prices of other food categories have mostly risen. Importantly, Hassen et al.'s (2016) data suggested that the prices per calorie of food commonly consumed by the poorest rural households, such as cassava, enset, and sorghum, showed a real price decline overall, with the important exception being pulses, and, given the importance of this food group for micronutrient adequacy, this again suggests the potential for deterioration in diet quality for the poorest.

While these data are somewhat problematic as they do not distinguish in a detailed way between the different prices paid by poorer and richer households in the same location (instead relying on price collection in a limited number of different locations), they do suggest that compiling nutritious food baskets with an appropriate balance of macro- and micro-nutrients has become more expensive over time.

Within the longer-run trends discussed in the Hassen et al. data, there have been two major periods of price spike, in 2008 and 2011. The causes of these food price spikes are debated. While the government (FDRE 2016a) suggests that the rise in global food prices and fuel prices was at the heart of domestic price rises in the GTP-I period (as do Durevall et al. 2013), Admassie (2014) argues that domestic factors were more salient. Admassie (2014) suggests the domestic food prices are relatively insulated from rises in world markets as more than 75 per cent of food consumption in Ethiopia is comprised of local staples (such as sorghum and teff) that are little traded internationally. Instead, Admassie points to currency devaluation and import restrictions as causing food price spikes. However, this ignores the greater role of food purchases in food provisioning (see also below on the monetization of food aid), and the importance of maize and wheat in household consumption, as well as the increased costs of fuel, fertilizer, and transportation. FAO (2014) in particular suggest that price rises in imported fertilizer have had a 
direct impact on food prices due to the high share of imported fertilizer in farm inputs in Ethiopia, despite the low use of fertilizer.

The food and fuel price rises of 2008 and 2011 caused significant balance of payments problems, and Table 22.2 shows the growing share of merchandise export revenue required to cover cereal imports, with the 3-year cereal import dependency ratio rising above 10 per cent in 2008-10 and 2009-11. Admassie (2014) notes the policy responses to stabilize food prices, including an export ban on cereals; attempts to reduce the money supply by raising the minimum deposit requirements for domestic banks; price controls; and action against speculative hording. FAO (2014) also note the distribution of subsidized food products (oil, wheat flour, and sugar) and the release of the strategic grain reserve - and we can see this as a key reason why GTP-I failed in its target to increase the national grain reserve. Indeed, FAO (2014) provides evidence that grain withdrawals from the national food reserve have substantially changed in character. Withdrawals for emergency operations reduced from 74 per cent (averaged over the period 1994-2009) to 28 per cent (averaged over the period 2005-9), whereas those intended for the safety net rose from 21 per cent (1994-2009) to 57 per cent (2005-9) and those for price stabilization increased from 5 per cent (averaged over the period 1994-2009) to 15 per cent (2005-9). Admassie (2014) argues that this release of wheat and maize helped to reduce the price of wheat in the domestic market.

However, this argument is weakened by the lack of data on the food prices paid by the poorest. What is clear from other evidence is that the bottom 10 per cent of rural households have actually suffered from declining consumption since 2005 and that inequality increased between 2000 and 2011 (see Chapter 18). 
Thus in the GTP-I period, there were significant increases in the real prices of some foods that seem to have eroded real consumer purchasing power, thereby challenging food security. In GTP-II, however, specific attention is given to food prices and the purchasing power of consumers. This is achieved through a focus on job creation and the establishment of foreign currency and physical food reserves to withstand international shocks (FDRE 2016a). It will be important to evaluate whether these strategies are successful in stabilizing food prices and consequently purchasing power, especially for the poorest.

\subsubsection{Food Processing and Market Distribution}

The National Nutrition Policy (NNP/NNP-I) particularly envisaged that industrial and trade policies would increase the affordability and attractiveness of a diverse set of food goods. There was a particular focus on fortified food, both domestically produced and imported, with the NNP-I intending that the domestic food and retail industry would encourage greater consumption of fortified products by consumers. However, these multisectoral elements of the NNP-I were found to be the most challenging.

The obstacles to integration of nutrition-sensitive policy across sectors were outlined in the National Nutrition Policy for the subsequent period (NNP-II) (FDRE 2016b: 20-1), which describes how 'Although multisectoral nutrition coordination and integration had been advocated on every forum and seemed to have improved over the last 5 years, most line ministries have lagged in mainstreaming nutrition into their sectoral strategic plans. This was especially true of efforts to cascade nutrition down to the implementation level.' The NNP-II describes why this may have happened: sectoral departments lacked effective organizational structures to mainstream nutrition; sectoral plans were not always reshaped to include nutrition goals; sectoral 
nutrition plans were not allocated a budget; responsibilities and accountabilities were not clearly defined around shared goals; and, finally, the mechanisms to capture nutrition-relevant data from all sectors were not developed (FDRE 2016b: 20-1).

The structure for multisectoral working was strengthened in the third iteration of the NNP, NNP-II (2016-20) (FDRE 2016b). NNP-II aimed to improve multisectoral working via three broad sets of actions: strengthening the NNCB and local coordination bodies; requiring ministries to establish new nutrition capacity; and establishing both new evidence and new evidence-based decision-making systems (2016b: 22-3).

\subsubsection{Food Transfers}

Using household expenditure data for 2011, Hassen et al. (2016) suggest that government donations and social security (mostly through the Productive Safety Net Programme (PSNP) and food aid) were relatively unimportant in both rural and urban areas in terms of funding food consumption, making up 2.3 per cent and 1.6 per cent of total food expenditures in urban and rural areas, respectively (2016). However, there is evidence that during this period, both direct transfers (through participation in social protection schemes) and indirect transfers (through the provision of subsidized products, discussed earlier) are likely to have increased.

The number of households in the PSNP did not fall as substantially as planned in the GTP-I, with 3.4 million enrolled in 2014/15 compared to the planned target of 1.3 million. As can be seen from the FAO (2014) and Admassie (2014), the PSNP has grown immensely since its inception in 2005, when it covered 5 million beneficiaries. In particular, there was rapid growth

during the food price spike of 2008, when PSNP beneficiary numbers increased to 8 million and donors also expanded non-PSNP food aid schemes (Admassie 2014). Between 45 and 65 per 
cent of PSNP beneficiaries (Klugman 2007) receive cash through cash-for-work and direct cash transfers. This shift from food provision to cash provision has led to several changes. First, the share of food aid has fallen in food imports, with direct food aid seen previously as a depressing influence on domestic food prices (Klugman 2007). While cash transfers are seen as stimulating local demand, Klugman (2007) raises concerns about their potential for creating price inflation.

While the PSNP is envisaged to expand over time in the latest version of the GTP (and thereby improve effective food demand) (FDRE 2016a: 24), there are critical voices. Sender (Chapter 18) reviews the evidence on the PSNP, concluding that there is clear evidence that the PSNP targeting has been poor, with significant use of it to bolster the political elite. Moreover, Gebrehiwot and Castilla's (2018) evaluation of the impact of the PSNP suggests several reasons for caution. Overall, while they found that the receipt of PSNP support increased calorie intake, there was no impact on child anthropometrics nor on dietary diversity. Gebrehiwot and Castilla (2018) suggest that one reason may be that the price of higher-quality food may have risen, particularly for animal-sourced foods, over the two years of their study. They were also concerned that the PSNP had not been paired with nutrition education messages about food quality and child feeding.

\subsection{CONCLUSIONS}

Our analysis suggests that there have been important changes in the effective demand for food in Ethiopia over recent years. Own production of food may be important for some rural households, but overall the data suggest that rural and urban households purchase a significant proportion of their food. Policy during the period 2010-15 focused on own-production access, and somewhat on food transfers and reducing food emergencies. The data suggest that direct food production 
may have risen for some rural households, but this was more likely to be the middle- and highincome rural households, while the real price of particular foods, particularly animal products and non-staple foods, rose sharply. This is worrying given the evidence of the impact of low dietary diversity on nutrition outcomes for adults and children. Food and cash transfers in this period increased as a result of government response to the food price spikes. This partly occurred through the increased numbers enrolled in the PSNP, and partly through the transfer of food aid and subsidized food products. The distribution of subsidized products will likely have helped improve calorie intake and, somewhat, dietary diversity (as wheat flour, oil, and sugar were distributed). However, it would not have aided in the consumption of animal-source protein, nor of fruit and vegetables, and there are reasons to be concerned that these transfers were poorly targeted and had little impact on the poorest.

These sharply rising prices were only partly caused by international food price spikes; other contributory causes were currency devaluation, monetization of food aid, and rapid shifts in urbanization. New policy (particularly as described in GTP-II) recognizes that stabilizing food prices is of crucial significance, not only to achieve inflation targets but also for food security. To stabilize food prices, two components of policy must be effective. First, there needs to be greater effective demand for food, not only for staples but also for a variety of products that provide essential micro-nutrients, and this will require either real price falls or greater productivity of own production. While agricultural policies will be relevant, so too will be industrial and trade policy. Improvements in the capacity to produce and import both fortified and non-fortified food are essential. To deal with instability in international markets, the government must build up both foreign exchange and a physical food reserve. At the same time, the domestic production of fertilizer and other agricultural inputs will also reduce the impact of 
international price peaks on final food prices. A second component of a broad policy around food affordability would focus on the creation of 'decent' work, i.e. the growth of employment opportunities associated with higher wages.

A final issue to raise is the implications if the government of Ethiopia finds it difficult to maintain cheap food, for either urban or rural households. Our discussion has focused on the implications for food and nutrition security. However, there are clearly implications for the dynamics of economic development. When real food prices rise, there are two likely outcomes. First, there may be pressures to increase real wages and in this way accumulation can be constrained. Headey et al. (2012) have argued that there is no empirical evidence that this has yet occurred in Ethiopia. This may well be due to the actions by the government of Ethiopia to dampen down the food price spikes. However, if continued action were needed, both foreign exchange and food reserves may not be sufficient, and greater wage pressures may emerge. Second, if the real price of food rises, it can reduce the disposable income available for non-food consumption, and in a domestic market as large as that of Ethiopia, this could have significant impacts on the potential market for nascent industrial sectors.

\section{References}

Admassie, A. (2014). 'Food Price Policy in an Era of Market Instability: A Political Economy Analysis', in The Political Economy of Food Price Policy in Ethiopia. Ed. Per PinstrupAndersen, Oxford University Press, pp.133-153

Baker, P., C. Hawkes, K. Wingrove, A. Demaio, J. Parkhurst, A.M. Thow, and H. L. Walls (2018). 'What Drives Political Commitment for Nutrition? A Review and Framework Synthesis to Inform the United Nations Decade of Action on Nutrition', BMJ Global Health 3 (1): $\mathrm{e} 000485$. 
Benson, T. (2005). Improving Nutrition as a Development Priority: Addressing Undernutrition within National Policy Processes in sub-Saharan Africa (Washington, DC: International Food Policy Research Institute).

Central Statistical Agency/Ethiopia and ICF International (2012). Ethiopia Demographic and Health Survey 2011 (Addis Ababa, Ethiopia: Central Statistical Agency and ICF International), Rockville, Maryland, USA).

Central Statistical Agency/CSA/Ethiopia and ICF (2016). Ethiopia Demographic and Health Survey 2016 (Addis Ababa, Ethiopia: Central Statistical Agency and ICF International, Rockville, Maryland, USA).

Central Statistical Agency and ICF International (2012, 2011). Ethiopia Demographic and Health Survey: Key Findings (Addis Ababa, Ethiopia: Central Statistical Agency and IFC International, Calverton, Maryland, USA).

Central Statistical Agency/Ethiopia and ORC Macro (2006). Ethiopia Demographic and Health Survey 2005 (Addis Ababa, Ethiopia: Central Statistical Agency and ORC Macro), Calverton, Marylad, USA).

Cramer, C., D. Johnston, D., C, Oya, and J. Sender (2017). 'Fairtrade and Labour Markets in Ethiopia and Uganda', Journal of Development Studies 53 (6): 841-56.

Devereux, S. (1988). 'Entitlements, Availability and Famine: A Revisionist View of Wollo, 1972-1974', Food Policy 13 (3): 270-82.

Ethiopian Academy of Science (2013). Report on Integration of Nutrition into Agriculture and Health in Ethiopia (Addis Ababa: Ethiopian Academy of Science).

Federal Ministry of Health (2008). 'National Nutrition Strategy'., Addis Ababa: Ministry of Health

FDRE (1996). 'National Food Security Strategy', Addis Ababa, Ministry of Health.

FDRE (2011). 'Growth and Transformation Plan (2010/11-2014/15).' Addis Ababa.

FDRE (2013). 'National Nutrition Programme: June 2013-June 2015', Addis Ababa.

FDRE (2016a). 'Growth and Transformation Plan II (GTP II) (2015/16-2019/20)', Addis Ababa.

FDRE (2016b). 'National Nutrition Programme II: 2016-20', Addis Ababa.

Fine, B. (1997). 'Entitlement Failure?', Development and Change 28 (4): 617-47.

FMoH/UNICEF/EU (2016). 'Situation Analysis of the Nutrition Sector in Ethiopia: 2000-2015', Ethiopian Federal Ministry of Health, UNICEF and European Commission Delegation. 
Food and Agriculture Organisation (FAO) (2014). 'Country Fact Sheet on Food and Agriculture Policy Trends', FAO.

Gebrehiwot, T. and C. Castilla (2018). 'Do Safety Net Transfers Improve Household Diets and Reduce Undernutrition? Evidence from Rural Ethiopia', Working Paper, Partnership for Economic Policy: Structural Transformation of African Agriculture and Rural Spaces.

Gillespie, S., L. Haddad, V. Mannar, N. Nisbett, and P. Menon (2013). 'The Politics of Reducing Malnutrition: Building Commitment and Accelerating Progress', Lancet, 382: 552-69.

Girard, A. W., J. L. Self, C. McAuliffe, and O. Olude (2012). 'The Effects of Household Food Production Strategies on the Health and Nutrition Outcomes of Women and Young Children: A Systematic Review', Paediatric and Perinatal Epidemiology 26 (s1): 205-22.

Hassen, I. W., M. Dereje, B. Minten, and K. Hirvonen, (2016). 'Diet Transformation in Africa: The Case of Ethiopia.' Working Paper 87, International Food Policy Research InstituteEthiopia Strategy Support Program (ESSP).

Hawkesworth, S., A. D. Dangour, D. Johnston, et al. (2010). 'Feeding the World Healthily: The Challenge of Measuring the Effects of Agriculture on Health', Philosophical Transactions of the Royal Society B: Biological Sciences 1554 (365): 3083-97.

Headey, D., F. B. Nisrane, I. Worku, M. Dereje, and A. S. Taffesse (2012) 'Urban Wage Behavior and Food Price Inflation: The Case of Ethiopia', Working Paper 41, Development Strategy and Governance Division, International Food Policy Research Institute-Ethiopia Strategy Support Program II.

Kalecki, M. (1993). 'The Problem of Financing Economic Development', in The Collected Works of Michal Kalecki: Volume 5, Developing Economies, ed. Jerzy Osiatynski, (Oxford: Clarendon Press): .

Kay, C. (2009). 'Development Strategies and Rural Development: Exploring Synergies, Eradicating Poverty', Journal of Peasant Studies 36 (1): 103-37.

Keller, E. J. (1992). 'Drought, War and the Politics of Famine in Ethiopia and Eritrea', The Journal of Modern African Studies 30 (4): 609-24.

Klugman, J. (2007). 'Ethiopia: Explaining Food Price Inflation', Discussion Paper No. 72898, World Bank, Washington, DC. 
Kuma T., M. Dereje, K. Hirvonen, and B. Minten (2018). 'Cash Crops and Food Security:

Evidence from Ethiopian Smallholder Coffee Producers', Journal of Development Studies, DOI:

$10.1080 / 00220388.2018 .1425396$

Malik, V. S., W. C. Willet, and F. B. Hu (2013). 'Global Obesity: Trends, Risk Factors and

Policy Implications', National Review of Endocrinology 9: 13-17.

Mendis, S. (2010). 'The Policy Agenda for Prevention and Control of Non-Communicable

Diseases', British Medical Bulletin 96: 23-43.

Ministry of Health (2015). 'Health Sector Transformation Plan (HSTP)', Ministry of Health, Federal Democratic Republic of Ethiopia.

Mulugeta, F. Z. (2010) 'The Contribution of Major Export Commodities of Ethiopia to the

Instability of the Country's Export Earnings', Working Paper, (TWP 1009), Trade Policy

Training Centre in Africa.

Reda, A. (2015). 'Achieving Food Security in Ethiopia by Promoting Productivity of Future

World Food Tef: A Review', Advances in Plants \& Agriculture Research 2 (2).

Reinhardt, K. and J. Fanzo (2014). 'Addressing Chronic Malnutrition through Multi-Sectoral,

Sustainable Approaches: A Review of the Causes and Consequences', Frontiers in Nutrition 1:

13.

Ruel, M. T., H. Alderman, and Maternal and Child Nutrition Study Group (2013). 'Nutrition-

Sensitive Interventions and Programmes: How Can They Help to Accelerate Progress in

Improving Maternal and Child Nutrition?' The Lancet 382 (9891): 536-51.

Secorun, L. (2016). 'Teff Could Be the Next Quinoa as Ethiopia Boosts Exports'.

https://www.theguardian.com/sustainable-business/2016/oct/14/teff-quinoa-ethiopia-boosts-

exports-food-africa

Sen, A. (1981). Poverty and Famines: An Essay on Entitlement and Deprivation (1st edn)

(Oxford: Clarendon Press).

Smith, L. C. and L. Haddad, L. (2015). 'Reducing Child Under-Nutrition: Past Drivers and

Priorities for the Post-MDG Era', Science Direct 11 (68): 180-204.

Swinburn et al. (2013), 'Monitoring and benchmarking government policies and actions', Obes

Rev. Suppl 1(2013): 24-37

Tadesse, G. and S. Gerald (2009). 'Food Aid, Food Prices, and Producer Disincentives in

Ethiopia', American Journal of Agricultural Economics 91 (4): 942-55. 
Tebekaw, Y., C. Teller, and U. Colon-Ramos (2014). 'The Burden of Underweight and Overweight among Women in Addis Ababa, Ethiopia’, BMC Public Health 14: 1126.

Turner, C., S. Kadiyala, A. Aggarwal, J. Coates, et al. (2017). 'Concepts and Methods for Food Environment Research in Low- and Middle-Income Countries', Agriculture, Nutrition and Health Academy Food Environments Working Group (ANH-FEWG). Innovative Methods and Metrics for Agriculture and Nutrition Actions (IMMANA) programme, London.

UNCTAD (United Nations Conference on Trade and Development) (2003). 'Economic Development in Africa: Trade Performance and Commodity Dependence', UNCTAD, Geneva. http://www.unctad.org

USAID (2016). 'Ethiopia'. https://www.usaid.gov/ethiopia.

USDA (United States Department of Agriculture) (2016). 'Ethiopia's Agriculture Imports Continue Growing', Global Agricultural Information Network, Addis Ababa.

De Waal, A. (1996). Famine Crimes: Politics and the Disaster Relief Industry in Africa (Oxford: James Currey).

Walls, H. L., S. Kadiyala, and R. D. Smith (2016). 'Research and Policy for Addressing Malnutrition in All its Forms', Obesity 24 (10): 2032.

Webb, P. and J. von Braun (1994). Famine and Food Security in Ethiopia: Lessons for Africa (Chichester: John Wiley \& Sons).

Zello, G. A. (2015). 'National Nutrition Programs in Emerging Countries: Coping with the Double Burden of Malnutrition and Obesity in Ethiopia', Canadian Journal of Diabetes 39: 4.

Table 22.1 Comparison of changes for average children and bottom asset quintile

$200520112016 \quad$ Percentage change (2005-16)

$\begin{array}{llcccc}\text { Stunting } & \text { all children } & 47 & 44 & 38 & -19 \% \\ & \text { bottom quintile } & 48 & 49 & 45 & -7 \% \\ \text { Underweight } & \text { all children } & 38 & 29 & 24 & -37 \% \\ & & & & & \\ & \text { bottom quintile } & 43 & 36 & 31 & -28 \%\end{array}$




$\begin{array}{llcccc}\text { Wasting } & \text { all children } & 11 & 10 & 10 & -10 \% \\ & \text { bottom quintile } & 13 & 12 & 14 & +8 \% \\ \text { Childhood } & \text { all children } & 54 & 44 & 57 & +6 \% \\ \text { anaemia } & \text { bottom quintile } & 60 & 48 & 68 & +13 \%\end{array}$

Sources: DHS data 2005 (CSA); DHS data 2011 (CSA/ICF 2012); DHS data 2016 (CSA/ICF 2016)

Table 22.2 Cereal import dependency ratio and value of food imports over total merchandise exports

Years Cereal import dependency ratio Value of food imports over

(\%) (3-year average) total merchandise exports (\%)

(3-year average)

$2005-7$

6.1

27

$2006-8$

7.2

30

2007-9

9.8

51

2008-10

11.9

60

2009-11

11.8

61

2010-12

9.3

55

2011-13 